\title{
Outpatient Tobacco Dependence Treatment for Individuals With Severe Mental Illness: The Butt Out Program Outcomes
}

\author{
Catherine L. Goldie \\ University of British Columbia \\ Etsuko Joy Masuhara \\ Vancouver Coastal Health Mental Health and Addictions Services \\ Tom Heah \\ Vancouver Coastal Health Mental Health and Addictions Services \\ Chizimuzo Okoli \\ University of Kentucky \\ Joy L. Johnson \\ University of British Columbia
}

\begin{abstract}
The Butt Out program is a tobacco dependence intervention that provides smoking cessation counselling and pharmacotherapy for clients with severe mental illness through Vancouver Community Mental Health Services. Participants received up to 24 weeks of pharmacotherapy for smoking cessation along with 12 weeks of behavioural therapy with another 12 weeks of group support. Based on an intent-to-treat analysis $(n=35)$, the end-of-treatment smoking abstinence rate was $8.6 \%$. For individuals who completed the
\end{abstract}

Catherine L. Goldie, PhD candidate, Nursing and Health Behaviour Research Unit, School of Nursing, University of British Columbia, Vancouver; Etsuko Joy Masuhara, MD, Vancouver Coastal Health Mental Health and Addictions Services; Tom Heah, Vancouver Coastal Health Mental Health and Addictions Services; Chizimuzo Okoli, Tobacco Treatment and Prevention Division, Tobacco Policy Research Program, University of Kentucky College of Nursing; Joy L. Johnson, Nursing and Health Behaviour Research Unit, School of Nursing, University of British Columbia, Vancouver.

Correspondence concerning this article should be addressed to Catherine Goldie, University of British Columbia School of Nursing, 302-6190 Agronomy Road, Vancouver, BC V6T 1Z3. Email: Katie.Goldie@nursing.ubc.ca 
program $(n=28)$, the abstinence rate was $10.7 \%$. Among program completers, $28.0 \%$ were able to achieve a $50 \%$ reduction to their baseline cigarette consumption. Due to the modest gains in abstinence and moderate improvements in smoking reduction achieved at the end of treatment, higher intensity programs of a longer duration may be indicated for future tobacco dependence interventions in psychiatric outpatient settings.

Keywords: tobacco, smoking cessation, psychotic disorders, mood disorders, community health services

Tobacco use remains the single most preventable cause of morbidity and mortality in Canada (Makomaski-Illing \& Kaiserman, 2004). Although overall smoking rates in the Canadian population have significantly declined in the last 50 years (Canadian Council on Tobacco Control, 2006), there are subsets of the population for whom quitting remains challenging, particularly for individuals with severe mental illness (SMI). A reliable population-level estimate of tobacco smoking among Canadians with SMI is needed; however, a recent clinical survey conducted with psychiatric outpatients $(n=729)$ in western Canada found that $46.8 \%$ of people with SMI reported high nicotine dependence levels and financial hardship imposed by purchasing tobacco products (Johnson et al., 2010). In the United States, estimates of tobacco use and concurrent lifetime and past-month mental illness are $34.8 \%$ and $41 \%$, respectively (Lasser et al., 2000). It has also been reported that individuals with nicotine dependence and a comorbid psychiatric disorder make up 7.1\% (95\% CI, 6.6-7.6) of the U.S. population yet consume $34.2 \%$ of the country's cigarettes (Grant, Hasin, Chou, Stinson, \& Dawson, 2004). These high rates of tobacco use increase the risk for tobacco-related mortality and morbidity and decrease quality of life for people with SMI (Osborn et al., 2007; Schmitz, Kruse, \& Kugler, 2003).

It is also important to recognize that many individuals with SMI are willing and motivated to quit smoking. A recent review suggests that more than $50 \%$ of individuals with mental illness are either contemplating quitting smoking in the next 6 months or are preparing to quit in the next 30 days (Siru, Hulse, \& Tait, 2009). Despite their willingness to quit smoking, studies have also shown that there are several barriers to individuals with SMI accessing appropriate smoking cessation interventions. Most importantly, smoking cessation interventions are not as frequent in the mental health field as they are in other health settings, few psychiatrists offer smoking cessation counselling to clients, and individuals with high nicotine dependency may require "off-label" doses of smoking cessation pharmacotherapy or a combination of nicotine replacement therapies (NRT) to relieve tobacco withdrawal symptoms and control breakthrough cravings (Himelhoch \& Daumit, 2003; Rose, Behm, Drgon, Johnson, \& Uhl, 2010; Sweeney, Fant, Fagerstrom, McGovern, \& Henningfield, 2001; Ziedonis \& Williams, 2003). Moreover, some psychiatric services continue to exploit the use of cigarettes as a means of behavioural reinforcement for patients (el-Guebaly, Cathcart, Currie, Brown, \& Gloster, 2002a; Jochelson, 2006).

Despite the existing challenges to accessing smoking cessation interventions, studies have shown that individuals with SMI can achieve successful smoking cessation. A review by el-Guebaly and colleagues (2002a) demonstrated that individuals with psychiatric illnesses respond to interventions that have been used in the general population and quit at similar rates (although at marginally lower rates of sustained abstinence as compared to the general population). However, most of these studies were efficacy trials, conducted under experimental conditions. A recent study by Selby, Voci, Zawertailo, George, and Brands 
(2010) compared retrospective data of smoking cessation outcomes between individuals with and without schizophrenia in an outpatient setting. They found that $23.6 \%$ of patients with schizophrenia as compared to $19.1 \%$ of matched controls (i.e., individuals without schizophrenia, and matched by age and gender) were abstinent at end of treatment.

Given the need for effective smoking cessation and reduction interventions offered to people with SMI in outpatient settings and the lack of studies assessing prospective findings, our current study reports on smoking abstinence and reduction behaviours of individuals with SMI who participated in a tobacco dependence treatment program.

\section{METHODS}

\section{Setting and Participants}

The Butt Out program provides tobacco dependence treatment under the auspices of Vancouver Coastal Health (VCH) Mental Health and Addictions Services for clients accessing community mental health centres. Clients using these services have a variety of mental illnesses that require long-term treatment from multidisciplinary professionals. Currently the Butt Out program has four operating sites at community mental health centres in Vancouver, British Columbia. To be eligible for the program, an individual must be (a) an existing client of VCH Mental Health Services, (b) 19 years or older, and (c) tobacco dependent. Individuals are not excluded based on their psychiatric diagnosis or their readiness to quit smoking.

\section{Intervention}

The Butt Out program consists of up to 24 weeks of tobacco dependence treatment, which includes pharmacotherapy and behavioural counselling.

Pharmacotherapy. Medication is dispensed weekly, at no cost to the client, and tailored to the participant's individual need. Medication includes the use of NRT (i.e., nicotine gum, patch, lozenge, inhaler), bupropion, and/or varenicline. A medication protocol was established for the Butt Out program in collaboration with the patient's physician and Butt Out group facilitator to determine the dose, duration of treatment, and simultaneous use of multiple products. A similar protocol has been previously used among individuals with co-occurring substance use and mental illness in addictions treatment settings (Khara \& Okoli, 2011).

Nicotine replacement therapy. Individuals who have high nicotine dependence $(>20$ cigarettes/day or Fagerström score 7-10) are given the choice of using a $21 \mathrm{mg}$ nicotine patch (daily) or nicotine gum/lozenge $4 \mathrm{mg}$ (q2hr) or nicotine inhaler 1 cartridge (q2hr), in addition to supplemental nicotine gum/lozenge $2 \mathrm{mg}$ or $4 \mathrm{mg}$ for cigarette cravings up to a maximum of 20 pieces/lozenges per day or a nicotine inhaler 1 cartridge up to a maximum of 12 per day to be used as needed for cigarette cravings. Individuals with moderate nicotine dependence (10-20 cigarettes/day or Fagerström score 4-6) are given the choice of using a nicotine patch $14 \mathrm{mg}$ (daily) or nicotine gum/lozenge $2 \mathrm{mg}$ (q2hr) or nicotine inhaler 1 cartridge (q2hr), in addition to supplemental nicotine gum/lozenge $2 \mathrm{mg}$ or $4 \mathrm{mg}$ for cigarette cravings up to a maximum of 20 pieces/ lozenges per day or a nicotine inhaler 1 cartridge up to a maximum of 12 per day to be used as needed for cigarette cravings. Individuals with low nicotine dependence ( $\leq 10$ cigarettes/day or Fagerström score $0-3)$ are given a nicotine patch $7 \mathrm{mg}$ (daily) or nicotine gum/lozenge $2 \mathrm{mg}$ or $4 \mathrm{mg}$ for cigarette cravings up to a 
maximum of 20 pieces/lozenges per day or a nicotine inhaler 1 cartridge up to a maximum of 12 per day to be used as needed for cigarette cravings. Group facilitators determine if it is clinically indicated to increase NRT patches by $7 \mathrm{mg}$ increments or to taper NRT to a lower dose. NRT doses are decreased or discontinued if new or worsening ischemia, new dysrhythmia, nausea, vomiting, tremor, or other signs of nicotine toxicity are present.

Bupropion and varenicline. Physicians are consulted prior to the use of these medications as there has been concern that they can impact client's mental status (Gunnell, Irvine, Wise, Davies, \& Martin, 2009). Both bupropion and varenicline are titrated prior to the individual's quit date. There is support in the literature for use of bupropion SR and NRT with higher cessation rates reported (Evins et al., 2007). The use of varenicline and NRT increases the risk of nicotine toxicity and is not currently recommended for combination therapy (Chandler \& Rennard, 2010). If indicated, bupropion SR is started 1-2 weeks before a client's quit date, starting at $150 \mathrm{mg} /$ day and titrating up to $150 \mathrm{mg}$ (twice a day). It is continued for 12 weeks or longer (up to 6 months if needed). Varenicline is started 1 week before quit date at $0.5 \mathrm{mg}$ (daily) for 3 days, then $0.5 \mathrm{mg}$ (twice a day) for 4 days, then $1 \mathrm{mg}$ (twice a day) for 12 weeks or longer (up to 6 months if needed). As the participants of the program have a total of 24 weeks to receive assistance in quitting, it is not uncommon for clients to set multiple quit dates within a 6-month period. All clients are monitored for depression using the Patient Health Questionnaire (PHQ-9), within the limitations of the group setting (Löwe, Kroenke, Herzog, \& Gräfe, 2004). If any concerns are noted, the client's physician and case manager are notified.

Behavioural counselling. Twelve weeks of structured group behavioural therapy sessions $\left(1 \frac{1}{2}\right.$ hours in duration) immediately followed by 12 weeks of support sessions ( $1 \frac{1}{2}$ hours in duration) are offered to clients. Behavioural therapy sessions are provided in a group format but tailored to individuals' needs by encouraging personal goal setting (reduction or cessation) and movement through the Stages of Change (Prochaska \& Norcross, 2001). Group sessions are facilitated by at least two health-care professionals (combinations of the following: occupational therapists, physicians, registered nurses, social workers, or registered psychiatric nurses) who have been trained to deliver the Butt Out program using a structured manual developed for the intervention. All group facilitators are also taught to integrate principles of motivational interviewing throughout their interactions with clients (Miller \& Rollnick, 2002).

The first two sessions focus on introducing facilitators and clients, describing the Butt Out program, establishing group norms and expectations, completing intake assessments and assessing each client's goals as well as quit/reduction dates. Sessions 3-6 focus on preparing for smoking reduction or cessation, and sessions 7-12 concentrate on teaching coping strategies and lifestyle changes once an individual has quit/ reduced smoking. Mid-point assessments are completed in week 12. In sessions 13-24, facilitators provide continued monitoring and support for smoking reduction or cessation and conduct end-of-treatment assessments in week 24 .

Each weekly group starts with a check-in session where clients share how much they are smoking and what their successes and struggles have been. Facilitators record smoking patterns, screen for depression, and monitor medication use. Educational material is then delivered in a modular approach using resources from the Butt Out manual before a group discussion is facilitated. Topics covered include health effects of smoking, strategies to quit/reduce smoking, nicotine withdrawal and toxicity, goal setting, managing cravings, smoking cessation aids, diet and nutrition, exercise and sleep, stress management, social support, and 
relapse prevention. At the end of each group, clients are encouraged to work on a specific goal for the week, and medications are dispensed. During the support phase, sessions start with a check-in or mindfulness/ relaxation exercise, and end with dispensing of medications.

\section{Program Completion and Follow-Up}

Treatment consists of a maximum of 24 weeks (i.e., 6 months). Program completion is determined by the number of group behavioural therapy sessions a client attends. Program completers are defined as individuals who attended at least 10 weeks of structured group behavioural therapy. Non-completers are those who are engaged in the program for more than 2 weeks beyond referral but have less than 10 weeks of attendance in the group program (individuals who missed more than two sessions of the structured 12-week group component, often as a result of uncontrollable life events such as hospitalizations and job situations, before disengaging from or dropping out of the program).

At 1 month after treatment completion, program completers were administered a telephone follow-up questionnaire to assess current tobacco use status. Follow-up with clients in this population is extremely difficult as it often requires multiple telephone calls $(\sim 5-10$ calls each) or contact with the client's case manager or physician if they do not have access to a telephone. Further, many clients refused to participate in follow-up phone calls during the consent process. No attempt was made to follow-up with non-completers due to time and budgetary constraints of the research team.

\section{Measures}

Baseline sociodemographic data were collected including gender, age, social supports for quitting (yes vs. no), age at daily smoking initiation, and evidence-based modalities used to quit smoking in the past (yes vs. no). In addition, information was recorded on history of other substance abuse (yes vs. no), primary mental health status (categorized as mood disorder/anxiety disorder vs. psychotic disorder), number of cigarettes smoked per day (CPD), Fagerström Test for Nicotine Dependence (FTND) scores (Beck, Steer, \& Carbin, 1988; Heatherton, Kozlowski, Frecker, \& Fagerström, 1991), and expired carbon monoxide (CO) level (Middleton \& Morice, 2000). Finally, at enrolment, participants were asked what their goal for the program was with the option of (a) smoking abstinence, (b) smoking reduction, and (c) unsure/uncertain.

Our primary outcome measure was smoking status at program completion (i.e., anytime within 12 weeks of completing the 12-week structured group behavioural therapy). Smoking cessation was defined as 7-day point-prevalence of smoking abstinence based on participant self-report with biochemical validation (expired $\mathrm{CO} \leq 8 \mathrm{ppm}$ ) when available. Smoking reduction was defined as reducing to $50 \%$ or less of cigarette use at admission to the program (but not quit). Seven-day point-prevalence of smoking status at 1-month follow-up was also assessed.

\section{Data Analysis}

Missing baseline data were replaced with the grand mean for continuous variables or median responses for categorical variables. Missing values for baseline and end-of-treatment $\mathrm{CO}$ level were replaced using a nextobservation-carried-backward (NOCB) or last-observation-carried-forward (LOCF) method, respectively, 
and the grand mean was imputed for cases without CO-level data (Selby et al., 2010). No greater than 25\% of the sample had scores imputed with the grand mean or modal response on any single variable.

Frequencies and means $(M)$ with standard deviations $(S D)$ were used to describe the characteristics of the sample. Smoking cessation and 50\% smoking reduction at 12 weeks (i.e., program midpoint) and at 24 weeks (i.e., program endpoint) were also portrayed using frequencies. Differences between those who completed the program and those who did not were calculated using chi-square for categorical and ordered categorical variables and independent sample t-tests with Levine's Test for equality of variance for continuous variables. All analyses were performed using the Statistical Package for the Social Sciences (SPSS) version 15.0. This study was approved by the University of British Columbia Behavioural Ethics Board, and all participants provided written informed consent.

\section{RESULTS}

\section{Sample Characteristics}

Of the 59 individuals who were referred to the Butt Out groups from September 2009 to May 2010, $24(40.6 \%)$ were not sufficiently engaged in the program (i.e., had two or fewer contacts with the program before leaving) and so were excluded from further analysis. The majority of these clients came to the first session and did not return. Baseline characteristics between those who remained engaged in the program (i.e., had more than two contacts, $n=35$ ) and those who were not sufficiently engaged in the program were examined and it was found that there were no differences in any sociodemographic variables or baseline variables of interest (i.e., confidence to quit, mental health diagnosis, nicotine dependence, or expired $\mathrm{CO}$ levels). A description of the sample is provided in Table 1. Program completers attended an average of 10 sessions and program non-completers attended an average of four sessions of group behavioural therapy.

Engaged participants $(n=35)$ were primarily male with a mean age of $47.1(S D=10.9)$ years. Half of the sample had a psychotic disorder and about one quarter had ever had a substance abuse problem (other than tobacco smoking). More than three quarters had ever used an evidence-based modality (i.e., NRT, counselling or both) in their past quitting attempts, and $77 \%$ had social support for quitting. Moreover, $80 \%$ ( $n=28 / 35$ ) of engaged participants completed the program. There were no baseline differences between program completers and non-completers on their age of daily smoking initiation, average CPD, nicotine dependence scores, or expired CO level. However, program completers were significantly older than noncompleters. Most of the engaged participants $(n=27 / 35)$ had biochemical validation of their reported smoking behaviours at baseline, and it was found that expired CO scores accurately reflected a participant's self-reported FTND score.

\section{Smoking Cessation}

In the intent-to-treat analysis (i.e., in which program non-completers are counted as treatment failures because they were lost to follow-up, $n=35), 5.7 \%(2 / 35)$ of participants achieved abstinence at the midpoint of the program (i.e., 12 weeks of group behavioural therapy) and 8.6\% (3/35) achieved abstinence at the end of treatment. In assessing only program completers, 7.1\% (2/28) achieved abstinence at the midpoint of treatment, and $10.7 \%(3 / 28)$ were abstinent at the end of treatment (see Figure 1). All program completers 


\section{Table 1}

Sample Characteristics

\begin{tabular}{|c|c|c|c|c|c|c|c|c|}
\hline & \multicolumn{2}{|c|}{$\begin{array}{c}\text { Total } \\
(N=35)\end{array}$} & \multicolumn{2}{|c|}{$\begin{array}{l}\text { Completers }^{\mathrm{b}} \\
\quad(n=28)\end{array}$} & \multicolumn{2}{|c|}{$\begin{array}{l}\text { Non-completers }{ }^{\mathrm{c}} \\
\quad(n=7)\end{array}$} & \multicolumn{2}{|l|}{ Difference* } \\
\hline & $n$ & $\%$ & $n$ & $\%$ & $n$ & $\%$ & $\begin{array}{c}\text { Chi-square } \\
\text { (degrees of freedom) }\end{array}$ & $p$ \\
\hline Gender & & & & & & & $.029(1)$ & .865 \\
\hline Female & 16 & 45.7 & 13 & 46.4 & 3 & 42.9 & & \\
\hline Male & 19 & 54.3 & 15 & 53.6 & 4 & 57.1 & & \\
\hline $\begin{array}{l}\text { Primary mental health } \\
\text { diagnosis }^{\mathrm{a}}\end{array}$ & & & & & & & $2.2(1)$ & .139 \\
\hline Mood/anxiety disorder & 14 & 50.0 & 10 & 43.5 & 4 & 80.0 & & \\
\hline Psychotic disorder & 14 & 50.0 & 13 & 56.5 & 1 & 20.0 & & \\
\hline History of substance abuse & & & & & & & $.60(1)$ & .439 \\
\hline Yes & 9 & 25.7 & 8 & 28.6 & 1 & 14.3 & & \\
\hline No & 26 & 74.3 & 20 & 71.4 & 6 & 85.7 & & \\
\hline $\begin{array}{l}\text { Evidence-based modalities } \\
\text { used to quit in the past } \\
\text { (i.e., NRT, medications, } \\
\text { counselling) }\end{array}$ & & & & & & & $0.0(1)$ & .847 \\
\hline Yes & 26 & 74.3 & 21 & 75.0 & 5 & 71.4 & & \\
\hline No & 9 & 25.7 & 7 & 25.0 & 2 & 28.6 & & \\
\hline $\begin{array}{l}\text { Social support for quitting } \\
\text { (i.e., family, friends, } \\
\text { counsellors in other treatment } \\
\text { programs) }\end{array}$ & & & & & & & $0.4(1)$ & .546 \\
\hline Yes & 27 & 77.1 & 21 & 75.0 & 6 & 85.7 & & \\
\hline \multirow[t]{2}{*}{ No } & 8 & 22.9 & 7 & 25.0 & 1 & 14.3 & & \\
\hline & Mean & $S D$ & Mean & $S D$ & Mean & $S D$ & $\begin{array}{c}\text { t-value } \\
\text { (degrees of freedom) }\end{array}$ & $p$ \\
\hline Age of participant (years) & 47.1 & 10.9 & 49.2 & 9.7 & 38.6 & 12.4 & $2.5(33)$ & $.019 *$ \\
\hline Age at daily smoking initiation & 17.3 & 6.9 & 17.7 & 6.9 & 15.6 & 8.5 & $0.7(33)$ & .472 \\
\hline Average CPD & 25.0 & 12.3 & 26.4 & 12.1 & 19.4 & 12.1 & $1.4(33)$ & .181 \\
\hline FTND at baseline & 6.8 & 1.6 & 6.9 & 1.6 & 6.4 & 1.4 & $0.7(33)$ & .497 \\
\hline $\mathrm{CO}$ level at baseline & 24.1 & 14.9 & 25.8 & 15.7 & 17.1 & 8.2 & $1.4(33)$ & .170 \\
\hline
\end{tabular}

Notes. NRT $=$ nicotine replacement therapy $; \mathrm{CPD}=$ cigarettes smoked per day; FTND $=$ Fagerström Test for Nicotine Dependence; $\mathrm{CO}=$ carbon monoxide.

${ }^{a}$ The mood/anxiety disorder category includes primarily individuals with depression and bipolar disorder and one individual with an anxiety disorder. The psychotic disorder category includes individuals with a primary past history of schizophrenia, schizoaffective disorder, and psychotic disorder. Only one participant had a personality disorder as the primary mental health diagnosis and was included in the psychotic disorder diagnosis group. Data on primary mental health diagnosis were missing for 7 individuals.

${ }^{\mathrm{b}}$ Program completers are individuals who attended at least 10 weeks of behavioural therapy sessions of the Butt Out program. ${ }^{\mathrm{c}}$ Program non-completers are individuals who had engaged in the program for more than 2 weeks, but attended less than 10 weeks of behavioural therapy sessions. 
who reported abstinence at the end of the program had their smoking status biochemically validated. There were no significant differences in end-of-treatment smoking cessation outcomes by gender $\left[\chi^{2}(d f=1)=0.23\right.$, $p=.630]$ or mental health diagnosis $\left[\chi^{2}(d f=1)=0.76, p=.385\right]$. Only $10 \%$ of program completers who had initially set a goal of smoking abstinence at program enrolment achieved their intended goal (see Table 2). At 1-month follow-up, 14.3\% (4/28) self-reported abstinence.

Figure 1

Smoking Cessation Outcomes at Midpoint and End-of-Treatment Among Program Completers $(n=28)$

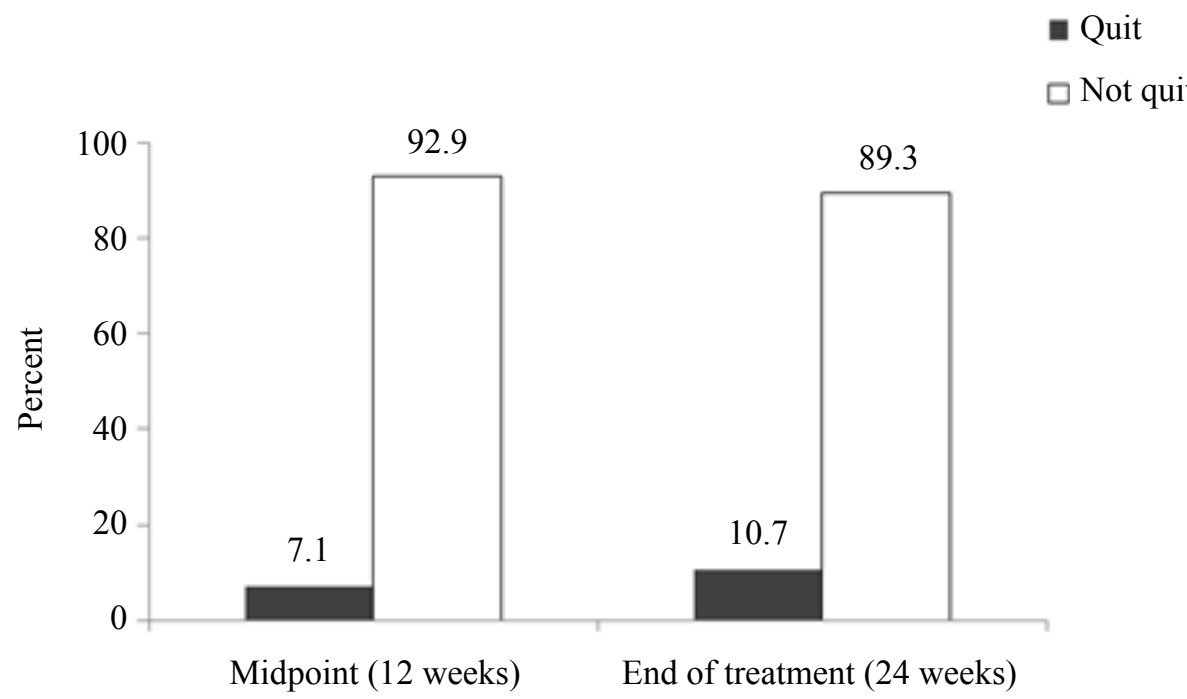

\section{Smoking Reduction}

Based on the intent-to-treat analysis (not including individuals who successfully quit smoking), 39.4\% (13/33) of participants successfully reduced their consumption to $50 \%$ of their baseline smoking rate at the midpoint of treatment and $21.9 \%$ (7/32) successfully maintained their smoking reduction by the end of treatment. In assessing only program completers, 50.0\% (13/26) achieved 50\% smoking reduction at the midpoint of treatment, and $28.0 \%$ (7/25) had reduced by the end of treatment (see Figure 2). Seventy-five percent of program completers who had initially set a goal of smoking reduction at program enrolment achieved their intended goal (see Table 2). 
Figure 2

Smoking Reduction Outcomes at Midpoint and End-of-Treatment Among Program Completers $(n=28)$

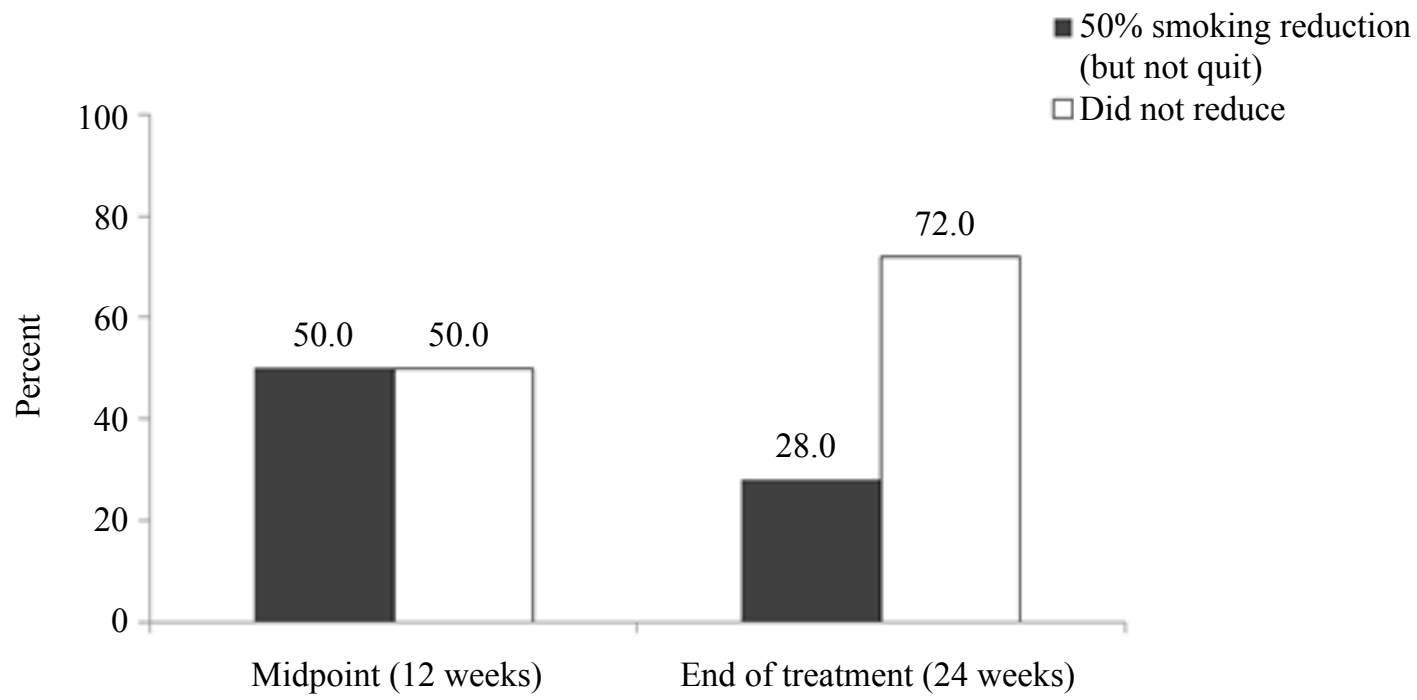

Table 2

Midpoint and End-of-Treatment Smoking Cessation and Reduction Outcomes Among Program Completers by Initial Treatment Goals Set by Participants at Baseline $(n=28)$

\begin{tabular}{lcccc}
\hline Baseline goal & $\begin{array}{c}\text { Midpoint cessation } \\
\text { outcomes }\end{array}$ & $\begin{array}{c}\text { Midpoint reduction } \\
\text { outcomes }\end{array}$ & $\begin{array}{c}\text { End-of-treatment } \\
\text { cessation outcomes }\end{array}$ & $\begin{array}{c}\text { End-of-treatment } \\
\text { reduction outcomes }\end{array}$ \\
\hline Abstinence $(n=20)$ & $10 \%$ & $65 \%$ & $10 \%$ & $35 \%$ \\
Reduction $(n=4)$ & $0 \%$ & $50 \%$ & $25 \%$ & $75 \%$ \\
Unsure $(n=4)$ & $0 \%$ & $0 \%$ & $0 \%$ & $0 \%$ \\
\hline
\end{tabular}

\section{DISCUSSION}

The aim of this study was to evaluate the smoking cessation and reduction outcomes of a tobacco dependence treatment program for individuals with SMI. End-of-treatment cessation was achieved by $10.7 \%$ of program completers, and reduction to $50 \%$ of baseline smoking was achieved by $28.0 \%$. Although it is still not conclusive whether smoking reduction confers any appreciative decrease in risk of mortality, smoking reduction may be an important marker of future successful smoking cessation (Godtfredsen, Holst, Prescott, Vestbo, \& Osler, 2002; Hughes \& Carpenter, 2006). In the review by Hughes and Carpenter (2006), eight 
randomized controlled trials were identified which demonstrated that smoking reduction interventions do not undermine smoking cessation.

The quit and reduction rates found in this study are lower than what has been previously reported in the literature. For example, a recent retrospective study evaluating a similar intervention in an outpatient smoking cessation program with persons with SMI $(n=165)$ found a $20.6 \%$ cessation and a $36.4 \%$ reduction rate at end of treatment (Selby et al., 2010). Another review of eight studies $(n=251)$ that examined smoking cessation approaches (i.e., NRT, behavioural therapy, clozapine or bupropion) used with persons with schizophrenia revealed end-of-treatment quit rates ranging from 35 to $56 \%$ (el-Guebaly, Cathcart, Currie, Brown, \& Gloster, 2002b). Although it has been suggested that severity of an individual's psychiatric condition can influence his or her quit rate (Gershon, Hwang, Han, George, \& Brody, 2007), we did not find any differences in smoking cessation outcomes by mental health diagnosis. Our findings, although attenuated by a low sample size, are similar to other studies which have found no difference in smoking cessation between individuals with psychotic disorders and individuals with other mental health diagnoses (Selby et al., 2010). However, a recent qualitative examination of smoking and cessation among individuals with SMI suggests that there are distinct differences in the ways in which diagnoses affect the use of tobacco and subsequent cessation motivation (Lawn, Pols, \& Barber, 2002). In light of these inconsistent findings, future studies with adequate sample sizes are indicated to further refine treatment strategies and explore smoking cessation by individual diagnosis.

A few limitations of our study are important to note in interpreting the findings. First of all, the relatively small sample size $(n=35)$ limited the further exploration of factors associated with program completion and smoking cessation using more high-level multivariate analysis. Second, this study lacked a control group, and so the findings should be interpreted with caution. Third, anecdotal evidence from the facilitators involved in this study suggests that actual abstinence and reduction rates were higher than reported. This may be the result of the conservative intent-to-treat analysis that was utilized or data collection procedures. Fourth, although attempts were made to obtain follow-up data from all program completers, we could not adequately assess smoking cessation status at 1 month after the end of treatment. Of 10 individuals who were administered follow-up questionnaires, 4 individuals claimed to remain abstinent from smoking, but this information could not be verified by objective $\mathrm{CO}$ monitoring.

\section{Conclusion}

The key findings of this evaluation include the relatively high retention in the program (i.e., 80\%) and the moderate smoking reduction achieved at the end of treatment. Providing evidence-based approaches to tobacco dependence treatment among individuals with SMI with no-cost pharmacotherapy may increase retention in such programs. However, the relatively poor smoking cessation outcomes at end of treatment may suggest the need for either more intensive programming (in terms of program components or duration of treatment) for individuals accessing outpatient smoking cessation services or more rigorous data collection procedures. Future studies will be required to assess the sustained effect of such interventions, and how treatment approaches may vary among individuals with different mental illness diagnoses. Such future programs may enhance smoking cessation and reduce the disproportionate disease burden of tobacco use in this population. 


\section{OUTPATIENT TOBACCO DEPENDENCE TREATMENT}

\section{RÉSUMÉ}

Les Vancouver Community Mental Health Services ont mis sur pied un programme appelé Butt Out qui consiste à offrir soutien et pharmacothérapie à des bénéficiaires souffrant de problèmes graves de santé mentale pour aider ceux-ci à cesser de fumer. Dans cet article, nous décrivons ce programme et nous analysons les résultats qu'il a permis d'obtenir auprès d'un groupe de participants. Ces participants ont pris pendant jusqu'à 24 semaines une médication pour les aider à se désaccoutumer du tabac, et ils ont suivi une thérapie comportementale pendant 12 semaines à la suite de laquelle ils ont participé à un groupe de soutien pendant 12 autres semaines. Sur la base de l'analyse des sujets retenus au début de l'essai clinique $(n=35)$, le taux d'abstinence au tabac à la fin du traitement a été de 8,6\%. Chez les individus qui ont terminé le programme $(n=28)$, ce taux a été de $10,7 \%$, et, parmi ces derniers, $28,0 \%$ ont réduit de $50 \%$ la consommation de cigarettes qu'ils faisaient au départ. Étant donné les gains modestes qu'a permis le traitement, en matière autant d'abstinence que de réduction de la consommation, nous pensons que des programmes plus intenses et de plus longue durée seraient nécessaires pour aider les patients externes en psychiatrie à lutter contre le tabagisme.

Mots clés : désaccoutumance au tabac, troubles psychotiques, troubles de l'humeur, services de santé communautaires

\section{REFERENCES}

Beck, A. T., Steer, R. A., \& Carbin, M. G. (1988). Psychometric properties of the Beck Depression Inventory: Twentyfive years of evaluation. Clinical Psychology Review, 8(1), 77-100.

Canadian Council on Tobacco Control. (2006). The 2006 progress report on moving forward. Retrieved January 18, 2012, from http://www.hc-sc.gc.ca/hc-ps/pubs/tobac-tabac/prtc-relct-2006/part1-eng.php

Chandler, M. A., \& Rennard, S. I. (2010). Smoking cessation. Chest, 137(2), 428-435.

el-Guebaly, N., Cathcart, J., Currie, S., Brown, D., \& Gloster, S. (2002a). Public health and therapeutic aspects of smoking bans in mental health and addiction settings. Psychiatric Services, 53(12), 1617-1622.

el-Guebaly, N., Cathcart, J., Currie, S., Brown, D., \& Gloster, S. (2002b). Smoking cessation approaches for persons with mental illness or addictive disorders. Psychiatric Services, 53(9), 1166-1170.

Evins, A. E., Cather, C., Culhane, M. A., Birnbaum, A., Horowitz, J., Hsieh, E., . . Goff, D. C. (2007). A 12-week double-blind, placebo-controlled study of bupropion SR added to high-dose dual nicotine replacement therapy for smoking cessation or reduction in schizophrenia. Journal of Clinical Psychopharmacology, 27(4), 380-386.

Gershon, G. R. B., Hwang, S., Han, J., George, T., \& Brody, A. L. (2007). Short-term naturalistic treatment outcomes in cigarette smokers with substance abuse and/or mental illness. Journal of Clinical Psychiatry, 68(6), 892-898.

Godtfredsen, N. S., Holst, C., Prescott, E., Vestbo, J., \& Osler, M. (2002). Smoking reduction, smoking cessation, and mortality: A 16-year follow-up of 19,732 men and women from the Copenhagen Centre for Prospective Population Studies. American Journal of Epidemiology, 156(11), 994-1001.

Grant, B. F., Hasin, D. S., Chou, S. P., Stinson, F. S., \& Dawson, D. A. (2004). Nicotine dependence and psychiatric disorders in the United States: Results from the national epidemiologic survey on alcohol and related conditions. Archives of General Psychiatry, 61(11), 1107-1115.

Gunnell, D., Irvine, D., Wise, L., Davies, C., \& Martin, R. M. (2009). Varenicline and suicidal behaviour: A cohort study based on data from the general practice research database. British Medical Journal, 339(b3805), 1-7.

Heatherton, T. F., Kozlowski, L. T., Frecker, R. C., \& Fagerström, K. O. (1991). The Fagerström test for nicotine dependence: A revision of the Fagerström Tolerance Questionnaire. British Journal of Addiction, 86(9), 119-127.

Himelhoch, S., \& Daumit, G. (2003). To whom do psychiatrists offer smoking-cessation counseling? American Journal of Psychiatry, 160(12), 2228-2230.

Hughes, J. R., \& Carpenter, M. J. (2006). Does smoking reduction increase future cessation and decrease disease risk? A qualitative review. Nicotine \& Tobacco Research, 8(6), 739-749.

Jochelson, K. (2006). Smoke-free legislation and mental health units: The challenges ahead. The British Journal of Psychiatry, 189(6), 479-480. 


\section{CANADIAN JOURNAL OF COMMUNITY MENTAL HEALTH}

Johnson, J., Ratner, P., Malchy, L., Okoli, C., Procyshyn, R., Bottorff, J., . . Osborne, M. (2010). Gender-specific profiles of tobacco use among non-institutionalized people with serious mental illness. BMC Psychiatry, $10(1), 101$.

Khara, M., \& Okoli, C. T. C. (2011). The tobacco dependence clinic: Intensive tobacco dependence treatment in an addiction services out-patient setting. The American Journal on Addictions, 20(1), 45-55.

Lasser, K., Boyd, J. W., Woolhandler, S., Himmelstein, D. U., McCormick, D., \& Bor, D. H. (2000). Smoking and mental illness. JAMA, 284(20), 2606-2610.

Lawn, S. J., Pols, R. G., \& Barber, J. G. (2002). Smoking and quitting: A qualitative study with community-living psychiatric clients. Social Science \& Medicine, 54(1), 93-104.

Löwe, B., Kroenke, K., Herzog, W., \& Gräfe, K. (2004). Measuring depression outcome with a brief self-report instrument: Sensitivity to change of the patient health questionnaire (PHQ-9). Journal of Affective Disorders, 81(1), 61-66.

Makomaski-Illing, E. M., \& Kaiserman, M. J. (2004). Mortality attributable to tobacco use in Canada and its regions, 1998. Canadian Journal of Public Health, 95(1), 38-44.

Middleton, E. T., \& Morice, A. H. (2000). Breath carbon monoxide as an indication of smoking habit. Chest, 117(3), 758-763.

Miller, W. R., \& Rollnick, S. (2002). Motivational interviewing: Preparing people for change. New York: Guilford Press.

Osborn, D. P. J., Levy, G., Nazareth, I., Petersen, I., Islam, A., \& King, M. B. (2007). Relative risk of cardiovascular and cancer mortality in people with severe mental illness from the United Kingdom's general practice research database. Archives of General Psychiatry, 64(2), 242-249.

Prochaska, J. O., \& Norcross, J. C. (2001). Stages of change. Psychotherapy, 38(4), 443-448.

Rose, J. E., Behm, F. M., Drgon, T., Johnson, C., \& Uhl, G. R. (2010). Personalized smoking cessation: Interactions between nicotine dose, dependence and quit-success genotype score. Molecular Medicine, 16(7-8), $247-253$.

Schmitz, N., Kruse, J., \& Kugler, J. (2003). Disabilities, quality of life, and mental disorders associated with smoking and nicotine dependence. American Journal of Psychiatry, 160(9), 1670-1676.

Selby, P., Voci, S. C., Zawertailo, L. A., George, T. P., \& Brands, B. (2010). Individualized smoking cessation treatment in an outpatient setting: Predictors of outcome in a sample with psychiatric and addictions co-morbidity. Addictive Behaviors, 35(9), 811-817.

Siru, R., Hulse, G. K., \& Tait, R. J. (2009). Assessing motivation to quit smoking in people with mental illness: A review. Addiction, 104(5), 719-733.

Sweeney, C. T., Fant, R. V., Fagerstrom, K. O., McGovern, J. F., \& Henningfield, J. E. (2001). Combination nicotine replacement therapy for smoking cessation: Rationale, efficacy and tolerability. CNS Drugs, 15(6), 453-467.

Ziedonis, D. M., \& Williams, J. M. (2003). Management of smoking in people with psychiatric disorders. Current Opinion in Psychiatry, 16(3), 305-315. 